\title{
Up Close: Institute of Electronic Structure and Lasers at the Foundation for Research and Technology-Hellas S.D. Peteves
}

This article is part of a series focusing on the research capabilities and goals of interdisciplinary laboratories pursuing materials research in universities, industry, and government

The Foundation for Research and Technology-Hellas (FORTH), Crete, Greece, was formally founded in December 1982 under the auspices of the Greek Secretariat of Research and Technology. Until recently the foundation was known as the Research Center of Crete.

Following the successful examples of university/research center cooperation in other countries, FORTH-although an independent institution-is strongly affiliated with the University of Crete. It was, in fact, the university's faculty who planned and proposed the creation of the center.

The foundation's goals have remained the same since its inception:

- To execute quality scientific and applied research in carefully selected and diverse areas,

- To support the evolution/development of high technology in Greece, both directly (e.g., specialized production activities and service offers) and indirectly (e.g., peerreview and consulting services to various national sectors, organizing and hosting scientific meetings), and

- To offer the means for developing graduate and training programs in frontier areas of science and technology.

Meeting these goals meant bypassing or at least alleviating inherent difficulties in Greece. These difficulties included, for example, lack of tradition in applied research, lack of support services, relative scientific isolation, and minimum national funding. (Among the EEC countries Greece still spends the least of its GNP for research and development.)
FORTH therefore based its founding strategies on a group of distinguished scientists, a network of state-of-the-art equipment, and an efficient form of organization. The strategies proved very effective. They facilitated the recruitment of other excellent Greek scientists from abroad, foreign and national visiting scientists, and postdoctoral fellows. But most importantly, they attracted substantial outside funding (mainly from EEC programs). FORTH's location on the island of Crete with its rich historical and intellectual background, natural beauty and excellent climate has also been among the assets contributing to the dynamic growth of the center.

The original organizational structure of the center included the central administration and the first five research institutes identified below. The current structure comprises the central administration and the following seven research institutes:

- Institute of Computer Science (ICS) with emphasis in applications.

- Institute of Applied and Computational Mathematics whose research is the numerical solution of equations pertinent to various branches of science and technology.

- Institute of Molecular Biology and Biotechnology, concentrating on research in molecular biology of selected organisms, in marine biology and the development of biotechnological applications.

- Institute of Mediterranean Studies, which studies the Mediterranean people from a historical, sociological, cultural, political and economic perspective and their interrelation with Greece.

- Institute of Electronic Structure and Lasers, concerned with materials science research.

- Institute of Chemical Engineering and High Energy Chemical Processes, affiliated with the University of Patras.

- Institute of Chemical Processing Technology, affiliated with the University of Thessaloniki.

The governing board includes the president and the directors of the institutes (who are mainly professors at the University of Crete), and a representative of the Greek Secretariat of Research and Technology.

\section{Institute of Electronic Structure and Lasers}

The Institute of Electronic Structure and Lasers (IESL) is concerned with materials science research, specifically with three main themes:

1. understanding the physical and electronic properties of materials for the purpose of developing applications in electronics,

2. the study of interactions between matter and laser beams, and

3 . the design of new lasers and related electro-optic devices.

Organization, Programs, and Personnel

The IESL currently has two divisions, each subdivided into groups pursuing a mixture of fundamental and applied research coherent with the main themes of the institute (see Table I).

IESL is staffed by 23 faculty members and research scientists, 5 postdoctoral fellows, 15 visiting scientists, 8 graduate students, and 12 technical and administrative personnel.

\section{Funding - Cooperation}

During 1987, IESL's budget was about 190 million Gr. drachmas (about US $\$ 1,357,000$ ). About $90 \%$ of the institute's total funding is obtained from sources outside Greece via proposals submitted either through the Greek government or directly from IESL to various European Community programs such as the Regional Fund, Mediterranean Integrated Program, ESPRIT, RACE, Brite, Stimulation etc., and the NATO program SFS. The institute's present income from specialized services and product activities amounts to about $40 \%$ of its total funding.

To achieve and maintain scientific excellence IESL from its inception sought to develop strong links with the international scientific community. As a result IESL has initiated numerous collaborations in the context of multilateral and bilateral agreements and also through direct contacts between laboratories and individual 


\section{Table I. Research at the Institute of Electronic Structure \& Lasers}

Lasers and Applications Division

$R \& D$ in Lasers and Laser Systems

- high power UV lasers

- lasers for diagnostics

- tunable VUV sources based on FWSM

Laser Applications

- materials processing

- semiconductor processing

- medical applications

Study of Nonlinear Phenomena

- multiphoton excitation (MPE)

- theory of MPE

Dynamics of Excited States

- state-selective energy transfer and reactivity

- fragmentation dynamics

- laser-induced clustering

Laser-Surface Interactions

- semiconductor annealing

- deposition of high $\mathrm{T}_{\mathrm{c}}$ superconducting films

Research, Development and Structure of New Lasers

\section{Materials and Devices Division}

GaAs Molecular Beam Epitaxy and III-V Mjcroelectronics

- GaAs MBE epitaxial wafers for microwave devices and integrated circuits

- epitaxy of GaAs on $\mathrm{Si}$

- laser/GaAs interactions

- GalnAs novel devices

- GaAs tunneling

- modeling of tunneling and heterojunctions

Characterization of Devices

- electrical

- optical

- structural

Refractory Silicides and Amorphous Metallizations

- study of WSi2, TiWSi2, VSi2, TaSi2 metal layers on GaAs $(n / n+$, Si)

- electrical behavior of metal on $n / n+$

- film interface evaluation

Amorphous Semiconductor Materials, Devices

- sputtering

- ionized cluster beam

Theoretical Group

- computational technique

- disorder of many body physics

- nonlinear dynamics

- applications of quantum field theory

researchers. During 1987, the institute maintained cooperative agreements with 5 Greek, 26 European and 9 U.S. universities or research centers, and 5 industrial firms.

\section{Facilities}

The IESL has access to FORTH's general state-of-the-art facilities such as the com- puter center, the structural and surface analysis unit, the digital image processing unit, the electronics department and others. In addition, the institute possesses its own high quality specialized equipmentfor example, two MBE systems, thin film deposition units, several laser systems (excimer, pulsed and continuous), photolithography system, IR and QM spectrometers, molecular ion beam system, and several characterization techniques for its grown wafers, including high energy electron diffraction, polaron DLTS system, profilometry, Van der Pauw-Hall effect measurements, and capacitance-voltage profiling.

\section{Conferences and Publications}

Apart from establishing graduate and training programs in collaboration with the University of Crete, the IESL acts as a discussion platform for the exchange of scientific ideas in its fields of interest. To implement this task, the institute has organized several international meetings such as the International Conference on Multiphoton Processes III, and the 14th International Conference on $\mathrm{GaAs}$ and $\mathrm{Re}$ lated Compounds. It also regularly hosts advanced summer institutes and workshops, seminars and mini-courses. The results of its research are widely published in the form of reports or in accredited scientific journals. In 1987 IESL's publications numbered about 35 .

\section{Present and Future Outlook}

IESL is in its fifth year, and the dynamic growth and achievements gained to date have resulted in the development of a new intellectual community in materials science in Greece.

IESL can claim major direct contributions to the development of high technology in Greece by harboring specialized production facilities and services and hence catalyzing the creation of new enterprises. For example, of two excimer lasers constructed in the IESL, one was sold to a Greek university. The institute's major success in this area, however, can be considered the molecular beam epitaxy laboratory, established for the research and development of new MBE materials and device structures. The laboratory can provide complete epitaxial film growth (GaAs, $\mathrm{GaAlAs}$, InGaAs, GaAs on Si etc.) services for a variety of application customers.

Greece critically needs to develop and further improve the competitiveness of its technology in the international marketplace. The limited research resource base must find new and effective ways to bring out and/or support domestic industry toward this vital end. IESL, a successful example of having gone beyond tradition, is a promising link with the advanced materials research and development network.

\section{Acknowledgments}

I am grateful to the Greek Secretariat of Research and Technology and particularly to Dr. Kiriakidis of IESL for providing me with all the necessary material for writing this report. Detailed information on the research, products, services, and publications of the IESL are available on request.

Institute of Electronic Structure and Lasers

Foundation of Research and

Technology - Hellas

P.O. Box 1527

Heraklion, Crete, Greece

Stathis D. Peteves is with the CeramicsMaterials Division, Institute for Advanced $\mathrm{Ma}$ terials, Joint Research Center, Petten, The Netherlands.

\section{If you can install a strip chart recorder.... You can AUTOMATE YOUR DATA COLLECTION} for under $\$ 2,000$ !

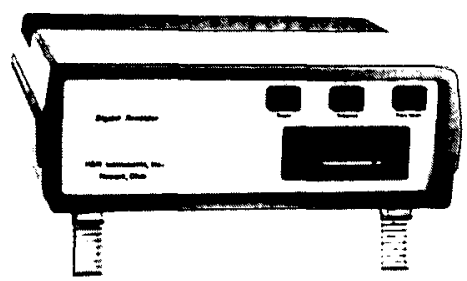

Our new digital recorder is simple to install and easy to use. It digitizes up to 8 separate analog input signals and stores them along with time onto $3 \frac{1}{2}$ " or $5 \frac{1}{4}$ " diskettes. Use your PC to subsequently analyze the data on the diskette. Or use our optional analysis package (software and/ or $\mathrm{PC}$ ).

Custom automation services also available.

H \& N Instruments, Inc. PO Box 955

Newark, OH 43055

(614) 345-7097 


\section{MATERIALS RESEARCH SOCIETY 1988 MRS Fall Meeting Symposium Proceedings Special Pre-Publication Prices Available Only Through March 1, 1989}

Volume 128

Processing and Characterization of Materials Using lon Beams

Editors: Lynn E. Rehn, Joe E. Greene, Fred A. Smidt, 1989

ISBN: 1-55899-001-1 Order Code: 128

MRS Members $\$ 39.00 \quad$ U.S. List $\$ 44.00 \quad$ Foreign $\$ 49.00$

Volume 129

Laser and Particle Beam Chemical Processes on Surfaces

Editors: A. Wayne Johnson, G.L. Loper, T.W. Sigmon, 1989

ISBN: 1-55899-002-X Order Code: 129

$\begin{array}{lll}\text { MRS Members } \$ 39.00 & \text { U.S. List } \$ 44.00 & \text { Foreign } \$ 49.00\end{array}$

Volume 130

Thin Films: Stresses and Mechanical Properties

Editors: John C. Bravman, William D. Nix, David M. Barnett, David A. Smith, 1989

ISBN: 0-55899-003-8 Order Code: 130

MRS Members $\$ 35.00 \quad$ U.S. List $\$ 43.00 \quad$ Foreign $\$ 48.00$

Volume 131

Chemical Perspectives of Microelectronic Materials

Editors: Mihal E. Gross, John T. Yates, Jr., Joseph Jasinski, 1989

ISBN: 0-55899-004-6 Order Code: 131

$\begin{array}{lll}\text { MRS Members } \$ 42.00 & \text { U.S. List } \$ 48.00 & \text { Foreign } \$ 54.00\end{array}$

Volume 132

Multicomponent Ultrafine Microstructures

Editors: B.H. Kear, D.E. Polk, R.W. Siegel, 1989

ISBN: 1-55899-005-4 Order Code: 132

$\begin{array}{lll}\text { MRS Members } \$ 35.00 & \text { U.S. List } \$ 42.00 & \text { Foreign } \$ 50.00\end{array}$

Volume 133

High Temperature Ordered Intermetallic Alloys

Editors: C.C. Koch, C. T. Liu, N.S. Stoloft, A.I. Taub, 1989

ISBN: 1-55899-006-2 Order Code: 133

$\begin{array}{lll}\text { MRS Members } \$ 42.00 & \text { U.S. List } \$ 50.00 & \text { Foreign } \$ 59.00\end{array}$

Volume 134

The Materials Science and Engineering of Rigid-Rod Polymers

Editors: W. Wade Adams, Ronald K. Eby, Donald E. McLemore, 1989

ISBN: 1-55899-007-0 Order Code: 134

MRS Members $\$ 42.00 \quad$ U.S. List $\$ 50.00 \quad$ Foreign $\$ 58.00$

Volume 135

Solid State lonics

Editors: Gholamabbas Nazri, Robert A. Huggins, Duward F. Shriver, P.T. Wu,

1989

ISBN: 1-55899-008-9 Order Code: 135

$\begin{array}{lll}\text { MRS Members } \$ 39.00 & \text { U.S. List } \$ 46.00 & \text { Foreign } \$ 55.00\end{array}$

Volume 136

Fly Ash and Coal Conversion By-Products: Characterization, Utilization and

Disposal $V$

Editors: E. E. Berry, R. T. Hemmings, G.J. McCarthy, 1989

ISBN: 1-55899-009-7 Order Code: 136

$\begin{array}{lll}\text { MRS Members } \$ 38.00 & \text { U.S. List } \$ 43.00 & \text { Foreign } \$ 51.00\end{array}$

Volume 137

Pore Structure and Permeability of Cementitious Materials

Editors: Lawrence R. Roberts, Jan P. Skalny, 1989

ISBN: 1-55899-010-0 Order Code: 137

MRS Members $\$ 35.00 \quad$ U.S. List $\$ 42.00 \quad$ Foreign $\$ 50.00$

Volume 138

Characterization of the Structure and Chemistry of Defects in Materials

Editors: Bennett C. Larson, Manfred Ruhle, David N. Seidman, 1989

ISBN: 1-55899-011-9 Order Code: 138

$\begin{array}{lll}\text { MRS Members } \$ 39.00 & \text { U.S. List } \$ 45.00 & \text { Foreign } \$ 54.00\end{array}$

Volume 139

High Resolution Microscopy of Materials

Editors: William Krakow, Fernando A. Ponce, David J. Smith, 1989

ISBN: 1-55899-012-7 Order Code: 139

MRS Members $\$ 38.00$

U.S. List $\$ 42.00$

foreign $\$ 50.00$

\section{Volume 140}

New Materials Approaches to Tribology: Theory and Applications

Editors: Larry E. Pope, Larry Fehrenbacher, Ward O. Winer, 1989

ISBN: 1-55899-013-5 Order Code: 140

MRS Members $\$ 39.00$

Foreign $\$ 52.00$

Volume 141

Atomic Scale Calculations in Materials Science

Editors: I Tersoff, D. Vanderbilt, V. Vitek, 1989

ISBN: 1-55899-014-3 Order Code: 141

MRS Members $\$ 34.00 \quad$ U.S. List $\$ 40.00$

Volume 142

Nondestructive Monitoring of Materials Properties

Editors: John Holbrook, Jean Bussiere, 1989

ISBN: 1-55899-015-1 Order Code: 142

MRS Members $\$ 34.00$ U.S. List $\$ 40.00$

Foreign $\$ 48.00$

Volume 143

Synchrotron Radiation in Materials Research

Editors: John H. Weaver, John Gland, Roy Clarke, 1989

ISBN: 1-55899-016-X Order Code: 143

MRS Members $\$ 35.00 \quad$ U.S. List $\$ 38.00$

Foreign $\$ 45.00$

Volume 144

Advances in Materials, Processing and Devices in III-V Compound

Semiconductors

Editors: Devendra K. Sadana, Lester Eastman, Russell Dupuis, 1989

ISBN: 1-55899-017-8 Order Code: 144

$\begin{array}{ll}\text { MRS Members } \$ 34.00 & \text { U.S. List } \$ 40.00\end{array}$

Foreign $\$ 48.00$

Extended Abstracts

Code EA-16

Graphite Intercalation Compounds; Science and Applications

Editors: M.S. Dresselhaus, G. Oresselhaus, 1989

MRS Members $\$ 10.00$

Code EA-17

Fractal Aspects of Materials: Disordered Systems

Editors: David A. Weitz, Leonard M. Sander, Benoit B. Mandelbrot, 1989

MRS Members $\$ 10.00$

Code EA-18

Selected Topics in Electronic Materials

Editors: B.R. Appleton, W.L. Brown, D.K. Biegelsen, J.A. Knapp, 1989

MRS Members $\$ 10.00$

The prices listed here are available only through

March 1, 1989. Prices after this date will be

higher. Order Now!

Publications Department

Materials Research Society

9800 McKnight Road, Suite 327

Pittsburgh, Pennsylvania 15237

Telephone (412) 367-3012

Fax (412) 367-4373 


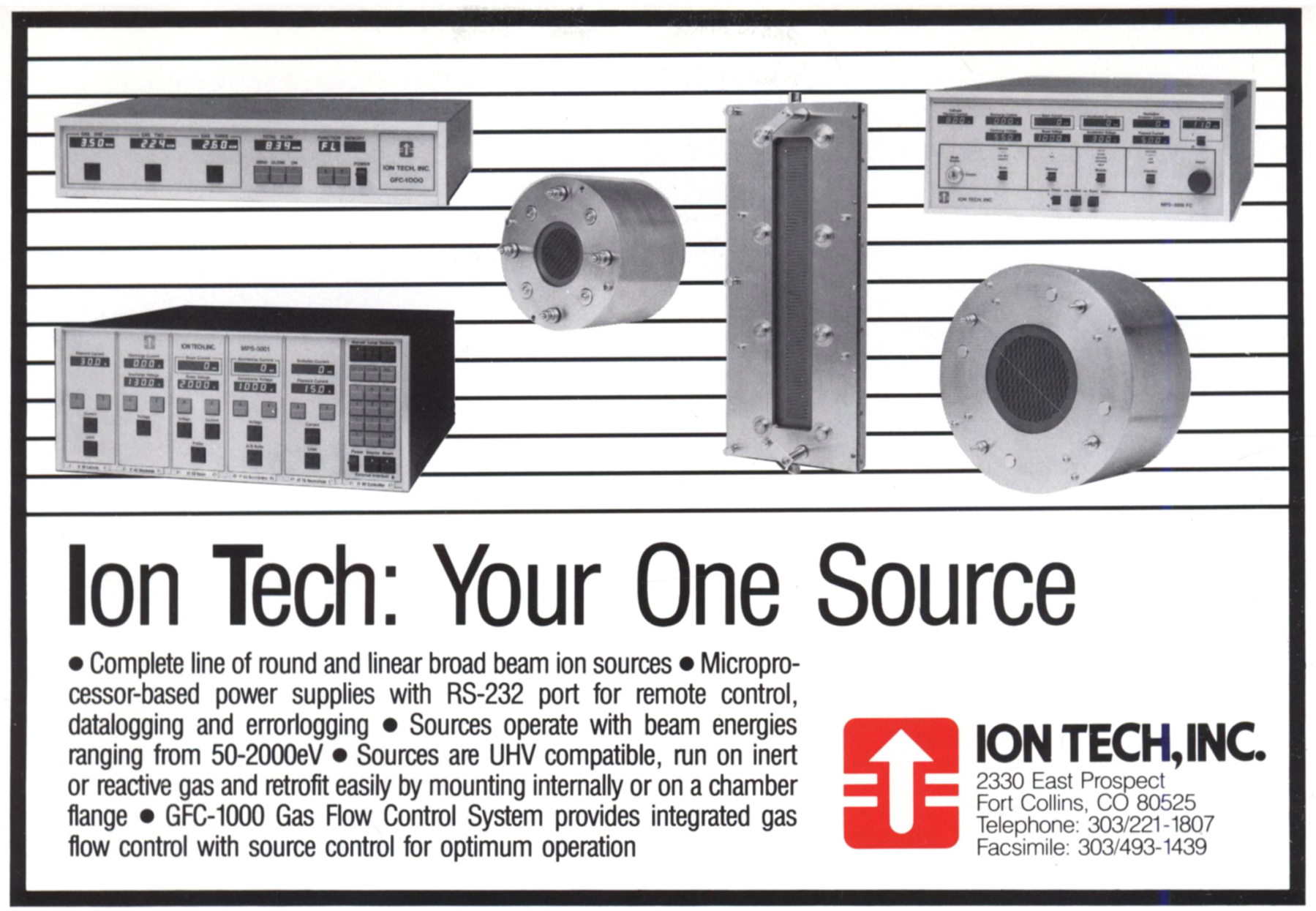

Please visit booth no. 501 at the MAS Show in Boston, November 29-December 1, 1988.

\section{AIP Journal Subscriptions Special Rates for MRS Members}

Members of the Materials Research Society are entitled to reduced-rate subscriptions on the following journals published by the American Institute of Physics.

Applied Physics Letters

Computers in Physics (New)

Current Physics Index

General Physics Advance Abstracts

Journal of Applied Physics

Journal of Chemical Physics

Journal of Mathematical Physics

Journal of Physical and Chemical Reference Data

Physics of Fluids- $A$

Physics of Fluids-B

Physics of Fluids-Both

Physics Today

Review of Scientific Instruments

$\begin{array}{r}\text { Dom } \\ \text { Member }\end{array}$
$\$ 55.00$
20.00
80.00
14.00
100.00
130.00
60.00
65.00
40.00
40.00
65.00
25.00
40.00

Domestic Rates

Nonmember

$\$ 485.00$

125.00

450.00

165.00

805.00

$1,335.00$

875.00

290.00

-

765.00

85.00

455.00
Foreign Rates

(Including

Canada \& Mexico)

Member Nonmember

$\$ 95.00 \quad \$ 525.00$

$30.00 \quad 135.00$

$105.00 \quad 475.00$

$29.00 \quad 180.00$

$150.00 \quad 855.00$

$205.00 \quad 1,410.00$

75.00

75.00

60.00

60.00

105.00

40.00

60.00
890.00

300.00

-

805.00

100.00

475.00

To subscribe, contact: Subscription Department, American Institute of Physics, 335 East 45th Street, New York, NY 10017; telephone (212) 661-9404. Be sure to indicate that you are a member of MRS. 